\title{
ROLE OF APELIN/MONOCYTE CHEMOATTRACTANT PROTEIN-1, INFLAMMATORY, APOPTOTIC MARKERS IN THE REGULATION OF PATIENTS WITH NON-ALCOHOLIC FATTY LIVER DISEASE
}

\author{
EMAN R YOUNESS ${ }^{1}$, HANAN FAROUK ALY ${ }^{2 *}$, M EL NEMR $^{3}$ \\ ${ }^{1}$ Department of Medical Biochemistry, National Research Centre, Dokki, Giza, P.0.12622, Egypt. ${ }^{2}$ Department of Therapeutic Chemistry, \\ National Research Centre, Dokki, Giza, P.0.12622, Egypt. ${ }^{3}$ Department of Internal Medicines, 6 October University, Cairo, Egypt. \\ Email: hanan_abduallah@yahoo.com
}

Received: 14 February 2018, Revised and Accepted: 23 April 2018

ABSTRACT

Objective: The objective of this study is to investigate blood nuclear factor $\kappa \mathrm{B}$ (NF-кB), apelin, lipid peroxide product; thiobarbituric acid (TBA) malonaldehyde (MDA), monocyte chemoattractant protein-1 (MCP-1), B-cell lymphoma 2 (Bcl2), and paraoxonase (PON1) levels in patients with non -alcoholic fatty liver disease (NAFLD) in a trail to correlate the significance of these biomarkers in the diagnosis and initiation of NAFLD patients.

Methods: A total of 32 patients with NAFLD and 45 healthy controls were enrolled in the study. Apelin levels were measured along with, NF- $\kappa B$, MCP1, MDA, Bcl2, and PON1 were detected.

Results: Significant increase in serum NF-кB, MDA, MCP1, and apelin levels in NAFLD patients with percentages increase 1031.23, 293.02, 165.93, and $120 \%$, respectively, while significant reduction in PON1 and BCl2 levels with percentages decrease 54.58 and $79.03 \%$, respectively, were detected as compared to control. A significant correlation was found between serum concentration of the measured biomarkers with the incidence of NAFLD.

Conclusions: It could be concluded that patients with NAFLD have significantly increased circulating apelin, NF- $\kappa$ B, and MDA levels as compared to healthy control subjects while significant reduction in BCl2 and PON1 levels were recorded. Besides, the NAFLD status is tightly attributed to the existence of insulin resistance and oxidative stress.

Keywords: Apelin, Adiponectin, Non-alcoholic fatty liver disease, Nuclear factor-кB, Monocyte chemoattractant protein-1, Bcl2, Paraoxanse1.

(C) 2018 The Authors. Published by Innovare Academic Sciences Pvt Ltd. This is an open access article under the CC BY license (http://creativecommons. org/licenses/by/4. 0/) DOI: http://dx.doi.org/10.22159/ajpcr.2018.v11i8.25281

\section{INTRODUCTION}

Non-alcoholic fatty liver disease (NAFLD) is a condition connected with various metabolic disorders [1]. The hepatic tissue is subjected to signals from other tissues organ, comprising adipose tissue, the gut, and its microbiota [2], involving a wide range of hepatic damage, extended from simple steatosis to steatohepatitis [3]. NAFLD can develop to non-alcoholic steatohepatitis (NASH) in $12-40 \%$ of conditions. NASH can be recognized by the finding of ballooning of hepatocyte, apoptosis, inflammatory infiltration, and deposition of collagen. The patients with NASH (15\%) will develop cirrhotic liver.

The mechanism of liver damage is not only the reason of fibrosis; but also apoptosis has been demonstrated, since it is considered as one of the great significant characteristics of NAFLD [4]. In addition, it has been found that Bax and caspase-3 are enhanced by cholesterol [5], which may be principle proteins for apoptosis; however, the p53 and Bcl-2 expression in steatotic cells did not elevate by cholesterol, speculating remarkable function for the mechanisms of cell death in hepatocytes [6].

Long-term exposure of mice to a high-fat diet (HFD) stimulates steatosis of hepatic tissue, altering the proteomes of liver mitochondria [7]. Dysfunction of mitochondria may be produced by reactive oxygen species (ROS) which suppress the respiratory chain and integrity of mitochondrial DNA participating in toxicity of organelle, inhibition of fatty acid (FA) oxidation and increase in lipid peroxidation [8]. Hepatic steatosis may be attributed to an increase in FA, glucose, lipotoxicity, or insulin resistance (IR), and it stimulates lipid synthesis (de novo mechanism) [9]. Moreover, peroxisome proliferator- activated receptor $\gamma$ causing an elevation in uptake of cellular free FA, more than the characteristic mechanism of hepatic lipid export and catabolism, supposing an adipogenic process of liver cells [10]. The presence of steatosis is closely associated with chronic inflammation of hepatic tissue, an effect mediated by signaling pathway activation of

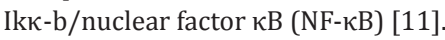

$\mathrm{NF}-\mathrm{B}$ is a protein that roles to stimulate a number of genes transcription, implicated in the regulation of the inflammatory response and cellular immunity [12]. Cytoplasmic nuclear factor- $\kappa \mathrm{B}(\mathrm{NF}-\mathrm{\kappa B})$ is an inactivated by inhibitory- $\mathrm{BB}(\mathrm{I} \kappa \mathrm{B})$, once activated it moves to the nucleus and acts to coordinate the enzymes transcription such as inducible nitric oxide synthase and cyclooxygenase- 2 cytokines such as interleukin (IL)-1 $\beta$, tumor necrosis factor (TNF)- $\alpha$, growth factors, immune receptors, and monocytes chemoattractant protein-1 (MCP-1) [13].

Apelin, a recently described adipocytokine, is abundantly expressed in adipose tissue and created in the endothelial cells [14]. In obese patients and in association with hyperinsulinemia, the plasma levels of apelin were found to be elevated [14].Further, it was found reduction in the levels of circulating apelin in patients with dyslipidemia and also newly diagnosed and untreated Type 2 diabetes mellitus (T2DM) [14].

The activity of paraoxonase (PON1) is varying related to PON1 consumption for the oxidation prevention [15]. As a matter of fact, PON1 has a principle function in atherosclerosis prevention [16].PON1 is an antioxidant enzyme linked with high-density lipoprotein (HDL) and shows a central role in the low-density lipoprotein (LDL) and HDL protection from oxidation through 
hydrolyzing the products of lipid peroxide and phospholipids [17]. PON1 decays the accumulation of LDL lipid peroxides on LDL and arteries in vitro and in vivo [18]. Further, serum activity of PON1 activity participates in the anti-atherogenic function of HDL, and its activity is tightly linked with oxidative stress in serum [19]. Hence, low PON1 activity in serum is considered a risk factor for coronary artery disease [20], hyperlipidemia [21], Type 2 diabetes [22], and renal dysfunction that is under oxidative stress [23]. In addition, Pasqualini et al. declared PON1 exhibits a principle effect in modulating endothelial function [24].

Hence, the present study is designed to evaluate the role of apelin, PON1, BCl2, MCP1, and NF-k $\beta$ as collective new diagnostic biomarkers in patients with NAFLD.

\section{METHODS AND SUBJECTS}

\section{Patients and inclusion criteria}

A total of 32 non-drinking patients (19 men and 13 women; mean age: $46.5 \pm 11.4$ years) with biopsy-proven NAFLD were enrolled into the prospective study in Hospital Clinic of National Research Centre. Informed consent was obtained from each patient. A total of 22 NAFLD patients with Insulin Resistance (IR) compared with 10 patients without IR. The patients were referred for the evaluation of tests of abnormal liver function and/or detection of hepatic steatosis, and hepatomegaly were carried out by ultrasonography (USG). The patients with alcohol intake (all patients were teetotalers) or with a history of recent potentially hepatotoxic drug intake were excluded from the study. Diagnosis was based on histology with exclusion of other etiologies such as chronic viral hepatitis, primary biliary cirrhosis, metabolic liver diseases, autoimmune liver disease, $\alpha 1$-antitrypsin deficiency, and Wilson's disease, hemochromatosis and sclerosing cholangitis. The fasting insulin level was measured, and the IR index was calculated using the homeostasis model assessment method: HOMA IR (\%): (glucose [mg/dl]/18)×(fasting insulin $[\mathrm{mU} / \mathrm{mL}] / 22.5$ ). The American Diabetes Association criteria for diabetes were applied. The patients with fasting serum glucose levels of more than $129 \mathrm{mg} / \mathrm{dl}$ or a 2 -h glucose level of more than $220 \mathrm{mg} / \mathrm{dl}$ during an oral glucose tolerance test were considered to have diabetes mellitus. After exclusion of the secondary NAFLD conditions, patients with elevated alanine aminotransferase (ALT), steatosis, or hepatomegaly in USG underwent liver biopsy. Biopsy materials that contained more than five portal areas were evaluated. According to HOMA IR, patients with biopsy-proven NAFLD diagnosis were then divided into two groups: IR group $(n=22)$ and non-IR group $(n=10)$. NASH was definitively diagnosed in all patients by histopathological examination following liver biopsy. A combination of hepatocellular steatosis, ballooning and disarray, acinar, or portal inflammation, and fibrosis in histopathological examinations was graded as Grade I (mild), Grade 2 (moderate), and Grade 3 (severe), and fibrosis was staged as stage one to four as suggested by the necroinflammatory grading and staging system for steatohepatitis [20]. Body mass index (BMI) was calculated as weight (in kilograms) divided by the square of height (in square meters) in all patients and controls. Cases were classified into three groups as normal weight group (BMI $<25 \mathrm{~kg} / \mathrm{m}^{2}$ ), overweight group (BMI $\geq 25-<30 \mathrm{~kg}$ / $\mathrm{m}^{2}$ ), and obese group (BMI $\geq 30 \mathrm{~kg} / \mathrm{m}^{2}$ ). Informed consent was obtained from the patients before the study. The National Research Centre Ethical Committee approved the study protocol and the procedures; these were in accordance with the blood samples collected in the morning after an overnight fast, and serum samples were stored at $-70^{\circ} \mathrm{C}$ until assay for PON1, BCl2, MCP1, and malonaldehyde (MDA) NF-k $\beta$.

None of the 45 healthy controls had any known disease, and none was taking any medications. Routine biochemical findings of the healthy controls individuals were also within the normal range. In all healthy controls, an abdominal ultrasound was performed to exclude bright liver. All controls had ALT and aspartate aminotransferase (AST) within normal range, were negative for hepatitis $C$ virus, hepatitis $B$ virus, and human immune deficiency virus infections or history of liver disease. Systolic and diastolic blood pressure was measured. Hypertension was defined as a systolic blood pressure of $140 \mathrm{mmHg}$ or more, a diastolic blood pressure of $90 \mathrm{mmHg}$ or more, or self-reported use of antihypertensive medications [25].

\section{Exclusion criteria}

Exclusion criteria included recent gastrointestinal bypass surgery, smoking habit, pregnancy, serum total bilirubin level higher than $2 \mathrm{mg} / \mathrm{dl}$, usage of estrogens, tamoxifen and glucocorticoids, rheumatoid arthritis, renal diseases, cancer, systemic or local infection, and history of excess alcohol ingestion, averaging more than $30 \mathrm{~g} /$ day (3 drinks per day) in the previous 10 years, or history of alcohol intake averaging $>10 \mathrm{~g} /$ day (1 drink per day: 7 drinks per week) in the previous 1 year [25].

\section{Blood sample collection}

Blood samples were obtained following an overnight fasting state. Samples were withdrawn from a cubital vein into blood tubes and immediately stored on ice at $4^{\circ} \mathrm{C}$. The serum was then separated from the cells by centrifugation at $3000 \mathrm{rpm}$ for $10 \mathrm{~min}$, and they were stored until analyzing at $-80^{\circ} \mathrm{C}$ [25].

\section{Assay of paraoxonase activity}

We measured the rate of hydrolysis of paraoxon by monitoring the increase of absorbance at $405 \mathrm{~nm}$ and at $25^{\circ} \mathrm{C}$. The basal assay mixture included 1.0 $\mathrm{mM}$ paraoxon and $1.0 \mathrm{mM} \mathrm{CaCl} 2$ in $0.05 \mathrm{M}$ glycine buffer, $\mathrm{pH} 10.5$. One unit (IU) of paraoxonase activity is defined as $1 \mu \mathrm{mol}$ of p-nitrophenol formed per min, and activity was expressed as U/l of serum [26].

\section{Determination of $\mathrm{MCP}-1$ protein}

MCP-1 protein levels in serum obtained from the study participants were measured using a solid-phase sandwich enzyme-linked immunosorbent assay (MCP-1 Quantikine ELISA kit, R and D systems, Abingdon, UK). Briefly, $100 \mu \mathrm{l}$ of duplicated samples or standards (recombinant human MCP-1) were incubated ( $2 \mathrm{~h}$ at room temperature) in the wells precoated with the primary antihuman MCP-1 antibody. After incubation, wells were washed three times and horseradish peroxidaseconjugated polyclonal antibodies against MCP-1 were added (for $2 \mathrm{~h}$ at room temperature). Finally, tetramethylbenzidine substrate solution was applied for $30 \mathrm{~min}$ and, after stopping the reactions by $2 \mathrm{M}$ sulfuric acid, the absorbance was measured at $450 \mathrm{~nm}$ (with correction at $540 \mathrm{~nm}$ ). The data were evaluated with KIM-E software (USOL, Prague, Czech Republic); the detection limit of the MCP-1 assay was $5.0 \mathrm{pg} / \mathrm{ml}$.

\section{Quantification of NF-кB}

$\mathrm{NF}-\kappa \mathrm{B}$ was measured in serum using commercially available human NF- $\kappa$ B enzyme-linked immunosorbent assay (ELISA) kit (Glory Science Co., Ltd., Del Rio, TX, USA) according to manufacturer instructions. The kit uses a double antibody sandwich ELISA to assay the level of NF- $\kappa$ B. The detection range of the kit is $100 \mathrm{U} / \mathrm{l}-2000 \mathrm{U} / \mathrm{l}$.

\section{Determination of lipid peroxide}

Lipid peroxidation was assayed in serum by measuring the thiobarbituric acid-reacting (TBA) substances as previously described by Ruiz-Larrea et al. [27] in which the thiobarbituric acid-reactive substances react with thiobarbituric acid to produce a red colored complex having peak absorbance at $532 \mathrm{~nm}$ (using ultraviolet-VI8 Recording Spectrophotometer (Shimadzu Corporation, Australia).

\section{Determination of Bcl-2}

The level of human B-cell leukemia/lymphoma 2 (Bcl-2) in striatal tissue was determined by double-antibody sandwich enzyme-linked immunosorbent assay kit according to the manufacturer's instructions (Biosystems, Egypt,).

\section{Determination of triglycerides (TGs)}

TG was measured by the method of Fossati and Prencipe [28] using a diagnostic kit (Biosystems, Egypt).

Insulin action was assumed to be related to the total daily insulin dose, which was calculated as dose per weight (ID $/ \mathrm{kg}$ ). Adiposity was estimated as BMI. Fasting plasma glucose was determined in serum by colorimetric assay according to Trinder [29]. Total cholesterol (TC) level was measured by the enzymatic colorimetric method according to the method of Richmond [30] (using a diagnostic kit Biosystems Spain). 
Apelin-12

Plasma apelin-12 levels were determined by ELISA (Human apelin-12 ELISA kit, Phoenix Pharmaceuticals, Belmont, CA, USA) (sensitivity: [Minimum detectable concentration] $=0.15-0.25 \mathrm{ng} / \mathrm{ml}$, IntraCV: 5\%and InterCV: 14\%).

\section{Liver function tests}

Alkaline phosphatase (ALP) was measured by the method of Belfield and Goldberg [31] using a diagnostic kit (Biosystems, Egypt). ALT and AST were determined in blood serum samples according to the method of Reitman and Frankel [32], using QCA Diagnostic kits (Spain). Serum gamma-glutamyl transferase activity was measured according to Persijn and van der Slik [33], using QCA Diagnostic kits (Spain).

\section{Statistical analysis}

We compared the data between the two groups using SPSS computer program version 8 coupled with co-state computer program, where unshared letters are significant at $\mathrm{p} \leq 0.05$.

\section{RESULTS}

The clinical data of study are demonstrated in Table 1 . There were no significant differences between two groups regarding to the age, gender, while a significant increase in BMI was detected in NAFLD patients $(p>0.01)$. The patients with NAFLD showed significant increase in serum TG, TC, AST, ALT, and ALP levels than controls ( $\mathrm{p}<0.05$ ) (Table 2). The grades of necroinflammatory and scores of fibrosis in the 32 patients with NAFLD were as follows: Grade 1 (mild) necroinflammatory changes, in 12 patients; Grade 2 necroinflammatory changes (moderate), in 13 patients; and Grade 3 (severe) necroinflammatory changes, in seven patients. Stage 0 Zone 3 fibrosis in peri-sinusoidal/cellular, in five patients; Stage 1, in seven patients; Stage 2, in 12 patients; and Stage 3 , in seven patients.

A total of 32 NAFLD patients were recognized through biopsies of the liver. A whole participant with the mean age was $46.5 \pm 11.4$ years. NAFLD patients with IR (more or less similar in age and gender) were compared with other NAFLD patients without IR. In the group of IR, the BMI was $29.32 \pm 4.25$, while another group (non-IR) was recorded as $29.51 \pm 3.12$. The patients with IR and without IR showed insignificant change, where they had $\mathrm{BMI} \leq 30$.

Table 3: Illustrated significant increase in NF- $\kappa$ B, MDA, MCP1, and apelin levels in NAFLD patients with percentages increase of 1031.23,

Table 1: The demographic variables and body composition in NAFLD and subjects

\begin{tabular}{llll}
\hline Variable & NAFLD & Control & p \\
\hline Gender $(\mathrm{M} / \mathrm{F})$ & $12 / 10$ & $8 / 16$ & NS \\
Age $($ year) & $46.5 \pm 11.4$ & $39.7 \pm 8.80$ & NS \\
BMI, kg/m ${ }^{2}$ & $30.32 \pm 4.25$ & $23.36 \pm 5.15$ & $<0.01$ \\
\hline
\end{tabular}

NAFLD: Non-alcoholic fatty liver disease, BMI: Body mass index.

Table 2: Biochemical and demographic parameters of NAFLD patients with and without IR

\begin{tabular}{llll}
\hline Biomarkers & Group without IR & Group with IR & p \\
\hline ALT (U/l) & $62.12 \pm 8.21$ & $88.12 \pm 30.23$ & 0.04 \\
AST (U/l) & $49.45 \pm 11.12$ & $62.20 \pm 25.14$ & 0.045 \\
Y GT (U/l) & $60.08 \pm 28.17$ & $65.96 \pm 48.16$ & NS \\
ALP (U/l) & $140.95 \pm 93.07$ & $142.04 \pm 82.55$ & NS \\
Cholesterol (mg/dl) & $219.1 \pm 66.70$ & $232.6 \pm 42.45$ & NS \\
TG (mg/dl) & $183.12 \pm 86.15$ & $192.4 \pm 74.86$ & NS \\
\hline
\end{tabular}

Data are presented as mean \pm standard deviation $(\mathrm{M} \pm \mathrm{SD})$, NS: Non-significant. NAFLD: Non-alcoholic fatty liver disease, NS: Statistically not significant, BMI: Body Mass Index, Y -GT: G-glutamyltranspeptidase, ALP: Alkaline phosphatase, ALT: Alanine aminotransferase, AST: Aspartate aminotransferase, IR: Insulin resistance
$293.02,165.93$, and $120 \%$, respectively, while significant reduction in PON1 and BCl2 levels with percentages decrease of 54.58 and79.03 \%, respectively.

\section{DISCUSSION}

Our results demonstrated that inhibition activity of serum PON1 in NAFLD patients. The mechanism underlying inhibition activity might have resulted from an elevation in ROS generation as presented by the detected high Levels of lipid peroxide product TBA. In addition, it was found that the expression of PON1 in HepG2 cells is down-regulated mRNA by proinflammatory cytokines such as IL-1 and TNF- $\alpha$ [34]. Hence, this decrease in production of PON1 in hepatic tissue by cytokine might be responsible for the decreased PON1 activity in serum of NAFLD patients. The inhibition activity of PON1 could be approved as another fact of high lipid peroxidation product which was recorded in the present study. PON1 showed also inhibition in its activity as an early biochemical alteration attributed to high level of lipid peroxidation in CCl4-induced liver damage [35]. In chronic liver disease, the PON1 inhibition activity was proposed to be correlated with to the degree of liver injury [26]. High level of MDA, a well-known lipid peroxidation product, and inhibition activity of PON1 in the present study reflect increased oxidative damage in patients with NAFLD. Hence, increased lipid peroxidation may be either a reason or a result of liver damage in NASH subjects. Besides, in the liver, the decrease in antioxidant in NAFLD may be due to their consumption by increased free radicals [35].

Further, in the present investigation, NAFLD induced significant increase levels of serum MCP-1. The chemokine MCP-1 is released by immune and non-immune cells linked with neuroinflammatory conditions as autoimmune encephalomyelitis, brain ischemia [12], posttraumatic secondary brain damage [36,37], and uveitis [38]. Mice with MCP-1 exhibited a reduced level of proinflammatory cytokines and fewer activated microglia, i.e. decreased brain inflammation in NFLD patients. In the hepatic tissue, MCP-1 has a principle function in the development of liver disease [39]. Hence, marked released MCP-1 amount by Kupffer cells stimulated by LPS [40]. In this study, the nonalcoholic fatty liver mediated increase in MCP-1.

MCP-1, also, is up-regulated in obese adipose tissue, secondary to macrophage infiltration [41]. Indeed, in mice adipose tissue, the specific overexpression of MCP-1 resulted in their development of IR, inflammation, and hepatic steatosis [41]. Hence, by macrophages, the signaling of MCP1-CCR2 has an important role in the inflammation and IR development. The pathway of MCP-1-CCR2 is also up-regulated in the animals hepatic tissue with NASH and is thus principle for hepatic steatosis and fibrosis development by eliciting hepatic stellate cells migration [42].

Our results showed also marked significant elevation in NF- $\kappa \mathrm{B}$ in serum of NAFLD patients. NF- $\kappa B$ is a protein transcription biomarker that can be stimulated in response to several factors such as cytokines and oxidative stress. It has a role in stimulating different transcription of genes such as cytokines, adhesion molecules, and immune receptors [43]. NF- $\mathrm{KB}$ signaling mediates liver injury in response to several agents or pathogens, brain edema in liver failure, neurogenesis, and depressive behavior due to long-term exposure to stress $[40,44]$.

The activation of NF- $\kappa \mathrm{B}$ is detected in patients with NASH as well as in animal models. NF- $\kappa \mathrm{B}$ and TNF- $\alpha$ are acted as inflammatory mediators in steatohepatitis [45], through stressed hepatocyte which produces pro-inflammatory pathways through NF- $\kappa B$ activation. Alternatively, NF- $\kappa B$-secreted different cytokines such as TNF- $\alpha$, IL- $1 \beta$, and other activated Kupffer cells and could activate NF- $\kappa B$ in neighboring hepatocytes [45].

In NAFLD, the fat accumulation may stimulate the release of TNF- $\alpha$, once this started, the cycle of NFkB/TNF- $\alpha$ becomes self-propagated [46]. It seems that long-term exposure to TNF- $\alpha$ cytokine elicits inflammatory cells accumulation in the hepatic tissue, as a result of that displaying hepatocytes to injurious, factors secreted by stimulated monocytes [46]. 
Table 3: Levels of specific biomarkers in patients with NAFLD

\begin{tabular}{lllllll}
\hline Groups/biomarkers & NF-kB (U/l) & TBA (nmol/L) & BCl2 $(\boldsymbol{\mu g} / \mathbf{l})$ & MCP1 (Pg/ml) & PON (kU/l) & Apelin (ng/l) \\
\hline Control & $48.54 \pm 9.00^{\mathrm{a}}$ & $2.15 \pm 0.05^{\mathrm{c}}$ & $12.40 \pm 0.06^{\mathrm{f}}$ & $7.25 \pm 0.91^{\mathrm{g}}$ & $230.00 \pm 11.90^{\mathrm{i}}$ & $400.00 \pm 23.90^{\mathrm{k}}$ \\
NAFLD & $549.10 \pm 5.87^{\mathrm{b}}$ & $8.45 \pm 0.02^{\mathrm{d}}$ & $2.60 \pm 0.03^{\mathrm{e}}$ & $19.28 \pm 1.00^{\mathrm{h}}$ & $125.00 \pm 10.88^{\mathrm{j}}$ & $880.00 \pm 21.89^{\mathrm{l}}$ \\
\% Change to control & 1031.23 & 293.02 & 79.03 & 165.93 & 54.58 & 120.00 \\
\hline
\end{tabular}

Data are presented as mean \pm standard deviation $(\mathrm{M} \pm \mathrm{SD})$ of 32 patients. NAFLD: Non-alcoholic fatty liver disease. Statistical analysis is carried out using SPSS computer program coupled with co-state computer program (version - 8), where unshared letters are significant at $P \leq 0.05$. NF- $\kappa \mathrm{B}$ : Nuclear factor $\mathbf{\kappa}$, TBA :thiobarbituric acid, MCP1: Monocyte chemoattractant protein-1

Regarding to Bcl-2, it is proteins family, and it plays a critical role in interfering with pathways of apoptosis. The mechanism of apoptosis comprises damage of the outer mitochondrial membrane integrity and releasing of cytochrome $\mathrm{C}$ and other proteins into the cytosol, which in turn activate apoptotic proteolytic caspases that regulate the dissociation of the cell, and this mechanism is adjusted by $\mathrm{BCl}-2$. By stopping proapoptotic protein, Bax, redistribution to the mitochondria, $\mathrm{BCl}-2$ blocks cytochrome $\mathrm{C}$ release from the mitochondria and subsequent caspase proteins activation [47]. $\mathrm{BCl}-2$ is characterized by its antioxidant activities and thus may have a great function in apoptotic and oxidative stress models of cellular damage. Our results showed decreased serum $\mathrm{Bcl}-2$ in the NAFLD which is run in parallel with other findings showed that hepatocyte death and/or apoptosis biomarkers are increased with the intensity of hepatic fibrosis in alcoholic patients [48].

Considering apelin, it is an adipokine that inhibits secretion of insulin in both in vivo and in vitro models by acting on insulin receptor in pancreatic $\beta$-cells [46]. The plasma levels of apelin are elevated in all the hyperinsulinemia associated with obesity in mice and humans [46].

Apelin joined with APJ, leading to protein kinase B(Akt) phosphorylation. The signaling pathway of Akt has been shown to correlate with cell migration. Also, the system of APJ/apelin stimulates the expression of intercellular adhesion molecule-1 via the signal pathway of NF-kB/cJun N-terminal kinase (JNK) [49]. In addition, Yasuzaki et al. [50], demonstrated that the signaling of apelin/APJ might elicit Faspromoted liver damage through JNK phosphorylation in mice injected with an anti-Fas antibody (Jo2) [50].

Long-term display of mice to HFD stimulates hepatic steatosis, altering the proteome of hepatic mitochondrial, such as modifies proteins incorporated in oxidative phosphorylation, folding of protein, lipid, and metabolism of sulfur amino acid [11]. High levels of ROS may be caused dysfunction of mitochondria which subsequent suppress respiratory chain and mitochondrial DNA integrity and also correlate with organelle toxicity, the inhibition of oxidation of FA and the elevation in lipid peroxidation [11]. Nonalcoholic fatty liver disease (NAFLD), a multifactorial disorder with contribution of a variety of genetic and environmental factors, is considered to be closely associated with hepatic metabolic disorders, resulting in over accumulation of fatty acids/triglycerides and cholesterol. The presence of steatosis is tightly associated with chronic hepatic inflammation, an effect in part mediated by activation of the Ikא-b/NF- $\mathrm{kB}$ signaling pathway. In murine models of high-fat diet induced steatosis, increased $\mathrm{NF}-\mathrm{KB}$ activity is associated with elevated hepatic expression of inflammatory cytokines such as TNF- $\alpha$ and activation of Kupffercells. $\mathrm{TNF}-\alpha$, a proinflammatory cytokine that is activated by the reactive oxygen species created by lipid peroxidation, not only promotes insulin resistance, but also mediates cholesterol and triglyceride metabolism. It promotes necroinflammation, fibrogenesis, hepatic insulin resistance, and apoptosis. Both serum and hepatic level of TNF- $\alpha$ are elevated in patients with NAFLD, and levels correlate with histological severity. Conversely, inhibition of TNF- $\alpha$ signaling improves IR and histological parameters of NAFLD [51]. Hepatic infiltration of leukocyte is caused by TNF- $\alpha$, participating in intracellular oxidative stress, and dysfunction of mitochondrial; in a matter of fact, receptor adaptor proteins of TNF promote mitogen-activated protein kinases phosphorylation which further stimulates c-JNK [11]. Longterm JNK signaling activation was found to enhance inflammation and apoptosis, magnifying hepatocyte injury [11].

IR and oxidative stress are the main features of NAFLD [52]. It was speculated that glycogenesis is suppressed by IR, induced gluconeogenesis and glycogenolysis and elevates the liberation of FFA from adipose tissue [52]. The influx of FA to the hepatic tissue and the development of lipotoxicity is the main reasons for the production of ROS and progression of disease from simple steatosis to NASH, which is a developing disease that can lead to cirrhosis and hepatocellular carcinoma [53].

IR is a leading cause of as declared by Leach et al. [54]; fasting glucose, insulin, and HOMA-IR were all markedly increase in NASH patients than normal group.

Diez-Rodriquez [55], illustrated that the high level of HOMA-IR is correlated with the necroinflammatory grade and the fatty liver severity was in particular contributed to IR by HOMA. Hence, in obese children, the biomarkers of insulin sensitivity could be helpful screening parameters for NAFLD [52].

The index of HOMA IR exhibited marked values for NASH differentiation. In addition, the ROC curves applied to confirm the distinctive potential of HOMA IR index for the necroinflammatory and fibrosis intensity and for distinguish NASH from simple fatty liver showed considerable rates. Patients with IR demonstrated markedly higher steatosis grade, necroinflammatory grade and stage [52].

\section{CONCLUSION}

Significant increase in MCP-1, NF KB, TBA product of lipid peroxidation and apelin levels, while significant reduction in $\mathrm{BCl} 2$ and $\mathrm{PON} 1$ was detected in non-alcoholic fatty liver patients. Besides, NAFLD pathogenesis is found to contribute to IR and oxidative stress.

\section{AUTHORS' CONTRIBUTIONS}

The first author has contributed to conception and design, acquisition of data to this study. The second (corresponding author ), and third authors have contributed for analysis, interpretation of data, drafting the article and gave the final approval for the version to submit.

\section{CONFLICT OF INTERESTS}

The authors declared non conflict of interest

\section{REFERENCES}

1. Bodakhe SH, Gupta SK. Diagnostic methods for non-alcoholic fatty liver diseases alternative to liver biopsy: A review. Asian J Pharm Clin Res 2015;8:54-9.

2. Singh G, Dhadwa N, Harikumar S. Experimental models for hepatotoxicity. Asian J Pharm Clin Res 2015;8:70-4.

3. Wincent MM, Potrilingam D, Anagha V, Jacob SC, Andhuvan G. Assessment of drug related problems in patients with chronic diseases in the general medicine units of a tertiary care hospital. Int J Pharm Pharm Sci 2017;9:194-200.

4. Yamaguchi H, Chen J, Bhalla K, Wang HG. Regulation of bax activation and apoptotic response to microtubule-damaging agents by p53 transcription-dependent and -independent pathways. J Biol Chem 2004:279:39431-7 
5. Lomonaco R, Sunny NE, Bril F, Cusi K. Nonalcoholic fatty liver disease: Current issues and noveltreatment approaches. Drugs 2013;73:1-14.

6. Zhu C, Xie P, Zhao F, Zhang L, An W, Zhan Y. Mechanism of the promotion of steatotic HepG2 cellapoptosis by cholesterol. Int J Clin Exp Pathol 2014;7:6807-13.

7. Eccleston HB, Andringa KA, Betancourt AM, Betancourt AL, Mantena SK, Swain TM, et al. Chronic exposure to a high-fat diet induces hepatic steatosis, impairs nitric oxide bioavailability, and modifies the mitochondrial proteome in mice. Antioxid Redox Signal 2011;15:447-59.

8. Bhardwaj A, Modi KP. Antidiabetic and antihyperlipidaemic activity of Nelumbo nucifera gaertnethanol seed extract in streptozotocin induced diabetic rats. Int J Pharm Pharm 2017;9:197-204.

9. Anderson N, Borlak J. Molecular mechanisms and therapeutic targets insteatosis and steatohepatitis. Pharmacol Rev 2008;60:311-57.

10. Al Sharif M, Alov P, Vitcheva V, Pajeva I, Tsakovska I. Modes of action related to repeated dose toxicity: Tissue-specific biological roles of PPAR ligand-dependent dysregulation in nonalcoholic fatty liver disease. PPAR Res 2014;2014:432647.

11. Nuño-Lámbarri N, Barbero-Becerra VJ, Uribe M, Chávez-Tapia NC. Mitochondrial molecular pathophysiology of nonalcoholic fatty liver disease: A proteomics Approach. Int J Mol Sci 2016;17:281, 1-12.

12. Abdel-Salam OM, Youness E, Adia A, Mohammed N, Abu Elhamed WA. Nuclear factor-kappa B and other oxidative stress biomarkers in serum of autistic children. Open J Mol Integ Physiol 2015;5:18-27.

13. Haddad JJ. Redox regulation of pro-inflammatory cytokines and $\mathrm{i} \kappa \mathrm{b}-\alpha / \mathrm{nf}-\kappa \mathrm{b}$ nuclear translocation and activation. Biochem Biophy Res Commun 2002;296:847-56.

14. Meral C, Tascilar E, Karademir F, Tanju IA, Cekmez F, Ipcioglu OM, et al. Elevated plasma levels of apelin in children with type 1 diabetes mellitus. J Pediatr Endocrinol Metabol 2010;23:497-502.

15. Aviram M, Rosenblat M, Billecke S. Human serum paraoxonase (PON1) is inactivated by oxidized low density lipoprotein and preserved by antioxidants. Free Radic Biol Med 1999;26:892-904

16. Watson AD, Berliner JA, Hama SY. Protective effect of high density lipoprotein associated paraoxonase. Inhibition of the biological activity of minimally oxidized low-density lipoprotein. J Clin Invest 1995;96:2882-91.

17. Canales A, Sanchez-Muniz FJ. Paraoxanase something more than an enzyme? Med Clin (Barc) 2003;121:537-48.

18. Mackness MI, Arrol S, Abbott C, Durrington PN. Protection of lowdensity lipoprotein against oxidative modification by high-density lipoprotein associated paraoxonase. Atherosclerosis 1993a;104:129-35.

19. Mackness MI, Abbott C, Arrol S. The role of high density lipoprotein and lipid-soluble antioxidant vitamins in inhibiting low-density lipoprotein oxidation. Biochem J 1993b;294:829-34.

20. Ayub A, Mackness MI, Arrol S. Serum paraoxonase after myocardial infarction. Arterioscler Thromb Vasc Biol 1999;19:330-5.

21. Mackness MI, Harty D, Bhatnagar D. Serum paraoxonase activity in familial hypercholesterolemia and insulin-dependent diabetes mellitus. Atherosclerosis 1991;186:193-6.

22. Abbott CA, Mackness MI, Kumar S. Serum paraoxonase activity, concentration, and phenotype distribution in diabetes mellitus and its relationship to serum lipids and lipoproteins. Arterioscler Thromb Vasc Biol 1995; 15:1812-8.

23. Sutherland WH, de Jong SA, Walker RJ. Hypochlorous acid and low serum paraoxonase activity in haemodialysis patients: An in vitro study. Nephrol Dial Transplant 2004;19:75-82.

24. Pasqualini L, Cortese C, Marchesi S. Paraoxonase 1 activity modulates endothelial function in patients with peripheral arterial disease. Atherosclerosis 2005;183:349-54.

25. Selek S, Aslan M, Nazligul Y. Serum PON1 activity and oxidative stress in non-alcoholic fatty liver disease. J Harran Univ Med Fac 2012;9:86-90

26. Bafikol M, Bafikol G, Denz K, Ozbakir O, Yucesoy MA. New marker for lipid peroxidation: Serum paraoxonase activity in non-alcoholic steatohepatitis. Turk J Gastroenterol 2005;16:119-23.

27. Ruiz-Larrea MB, Leal AM, Liza M, Lacort M, de Groot H. Antioxidant effects of estradiol and2-Hydroxyestradiol on iron-induced lipid peroxidation of rat liver microsomes. Steroids 1994;59:383-8.

28. Fossati P, Prencipe L. Serum triglycerides determined colorimetrically with an enzyme that produces hydrogen peroxide. Clin Chem 1982:28:2077-80

29. Trinder P. Determination of glucose in blood using glucose oxidase with an alternative oxygen receptor. Ann Clin Biochem 1969;6:24-7.

30. Richmond W. Preparation and properties of a cholesterol oxidase from Nocardia sp. and its application to the enzymatic assay of total cholesterol in serum. Clin Chem 1974;19:1350-6.
31. Belfield A, Goldberg D. Colorimetric determination of alkaline phosphatase activity. Enzyme 1971;12:561-6.

32. Reitman S, Frankel S. A colourimetric method for the determination of serum glutamic oxaloacetic and glutamic pyruvic transaminases. Am J Clin Pathol 1957;28:56-62.

33. Persijn JP, van der Slik W. A new method for the determination of gamma-glutamyltransferase in serum. Clin Chem Lab Med $1976 ; 14: 421-7$

34. Kumon Y, Nakauchi Y, Suehiro T. Proinflammatory cytokines but not acute phase serum amyloid A or reactive protein, down-regulates paraoxonase 1 (PON1) expression by HepG2. Amyloid 2002;9:160-4.

35. Ferre N, Camps J, Cabre M. Hepatic paraoxonase activity alterations and free radical production in rats with experimental cirrhosis. Metabolism 2001;50:997-1000.

36. Andjelkovic AV, Kerkovich D, Pachter JS. Monocyte: Astrocyte interactions regulate MCP-1 expression in both cell types. J Leukoc Biol 2000;68:545-52

37. Semple BD, Bye N, Rancan M, Ziebell JM, Morganti-Kossmann MC. Role of CCL2 (MCP-1) in traumatic brain injury (TBI): Evidence from severe TBI patients and CCL2- mice. J Cereb Blood Flow Metab 2010;30:769-82.

38. Tuaillon N, Shen DF, Berger RB, Lu B, Rollins BJ, Chan CC. MCP-1 expression in endotoxin-induced uveitis. Invest Ophthalmol Vis Sci 2002;43:1493-8

39. Mandrekar P, Ambade A, Lim A, Szabo G, Catalano D. An essential role for monocyte chemoattractant protein-1 in alcoholic liver injury: Regulation of proinflammatory cytokines and hepaticsteatosis in mice. Hepatology 2011;54:2185-97.

40. Abdel-Salam OM, Youness ER, Omara EA, Sleem AA. Effect of adipose tissue-derived mesenchymal stem cell treatment on oxidative stress and inflammatory response following Escherichia coli lipopolysaccharide. Comput Clin Pathol 2014;23:65-80

41. Kitade H, Chen G, Ni Y, Ota T. Nonalcoholic fatty liver disease and insulin resistance: New insights and potential new treatments. Nutrients 2017;9:387-400.

42. Miura K, Yang L, van Rooijen N, Ohnishi H,Seki E. Hepatic recruitment of macrophages promotesnonal coholicsteatohepatitis through CCR2. Am J Physiol Gastrointest 2012;302:G1310-21.

43. Chen F, Castranova V, Shi X, Demers LM. New insights into the role of nuclear factor-kappaB, a ubiquitous transcription factor in the initiation of diseases. Clin Chem 1999;45:7-17.

44. Koo JW, Russo SJ, Ferguson D, Nestler EJ, Duman RS. Nuclear factorkappaB is a critical mediator of stress-impaired neurogenesis and depressive behavior. Proc Natl Acad Sci 2010;107:2669-74.

45. Cerpa-Cruz S, González-Díaz V, Martínez-Bonilla G, GutiérrezUreña S, Rodríguez-Cortés E, et al. Non-Alcoholic fatty steatohepatitis an inflammatory disorder beyond the Liver. J Clin Cell Immunol 2013;4:2-8

46. Baranova A, Younossi ZM. Fantuzzi G, Mazzone T, editor. Adipokines in Non-Alcoholic Fatty Liver Disease. Nutrition and Health: Adipose Tissue and Adipokines in Health and Disease. Totowa, NJ: Humana Press Inc.; 2007. p. 291-305.

47. Lavallard VJ, Gual P. Autophagy and non-alcoholic fatty liver disease. Biomed Res Int 2014;2014: Article ID: 120179, 13.

48. Lavallard VJ, Bonnafous S, Patouraux S. Serum markers of hepatocyte death and apoptosis are noninvasive biomarkers of severe fibrosis in patients with alcoholic liver disease. PLoS One 2011;6:e17599.

49. Lu Y, Zhu X, Liang GX, Cui RR, Liu Y, Wu SS. Apelin-APJ induces ICAM-1, VCAM-1 and MCP-1 expression via NF-kB/JNK signal pathway in human umbilical vein endothelial cells. Amino Acids 2012;43:2125-36.

50. Yasuzaki H, Yoshida S, Hashimoto T, Shibata W, Inamori M, Toya Y. Involvement of the apelin receptor APJ in Fas-induced liver injury. Liver Int 2013;33:118-26.

51. Wang YL, Liu LJ, Zhao WJ, Li JX. Intervening TNF- via PPAR with gegenqinlian decoction in experimental nonalcoholic fatty liver disease. Evid Based Complement Altern Med 2015;2015:715638.

52. Koroğlu E, Canbakan B, Atay K, Hatemi İ, Tuncer M, Dobrucalı A, et al. Role of oxidative stress and insulin resistance in disease severity of non-alcoholic fatty liver disease. Turk J Gastroenterol 2016;27:361-6.

53. Cohen JC, Horton JD, Hobbs HH. Human fatty liver disease: Old questions and new insights. Science 2011;332:1519-23

54. Leach NV, Dronca E, Vesa SC. Serum homocysteine levels oxidative stress and cardiovascular risk in non-alcoholic steatohepatitis. Eur J Int Med 2014;25:762-7.

55. Diez-Rodriquez R. Insulin resistance and metabolic syndrome are related to non-alcoholic fatty liver disease, but not visceral adiposity index, in severely obese patients. Rev Esp Enferm Dig 2014;106:522-8. 